\title{
From the USDA: Educating the Next Generation: Funding Opportunities in Food, Agricultural, Natural Resources, and Social Sciences Education
}

Joyce E. Parker* and David J. Wagner

Division of Community and Education, National Institute of Food and Agriculture, U.S. Department of Agriculture, Washington, DC 20250-2201

\begin{abstract}
The National Institute of Food and Agriculture within the U.S. Department of Agriculture provides leadership, capacity, and funds to support the continuing development of a safe and competitive agricultural system. Many of the agency's educational programs are led by the Division of Community and Education (DOCE). These programs span agricultural education, enhancing agricultural literacy through both formal and nonformal education. Here, we have highlighted funding opportunities within DOCE that enhance agricultural education and literacy by supporting the improvement of students' critical communication, leadership skills, and experiential learning opportunities. Some of these programs include opportunities for which students can apply, while others focus on faculty applications. Opportunities faculty can apply for may support student-recruitment and student-retention techniques, curriculum development, innovative teaching methods, and institutional capacity-building programs. Overall, these programs foster a diverse workforce in agricultural science that matches the increasing diversity of the country.
\end{abstract}

\section{INTRODUCTION}

The global population is expected to grow to nine billion by 2050. Meeting the increasing demands for food, fiber, and fuel sustainably will require innovative solutions generated by a diverse workforce of well-trained agricultural scientists and natural resource managers. Job opportunities for science, technology, engineering, and mathematics (STEM) graduates in the food, agricultural, human (social sciences), natural resources, and environmental sciences areas are expected to grow, and these graduates will be needed to help provide solutions to this grand challenge. For example, Employment Opportunities for College Graduates in Food, Agriculture, Renewable Natural Resources, and the Environment 2015-2020 (Goecker et al., 2015) reported more than 50,000 annual openings for graduates with bachelor's or higher degrees in these areas. There is a growing appreciation of the importance of expanding student participation in these sciences by advancing education opportunities, particularly for underrepresented groups (Allen and Woodin, 2009). One also sees a movement toward more interdisciplinary and interconnected approaches and themes for education in the life sciences (Labov et al., 2010), something that is inherent in agricultural and environmental work. The important questions are as follows: 1) Is the United States producing enough students with the necessary skills needed to fill the employment forecast?, and 2) Is the United States generating a diverse workforce equivalent to its quickly changing demographics?

Many U.S. Department of Agriculture (USDA) agencies support and promote both formal and nonformal education programs. The National Institute of Food and Agriculture (NIFA) is one of 18 agencies within the USDA and provides leadership, capacity,
CBE Life Sci Educ September 1, 2016 15:fe5 DOI:10.1187/cbe.16-01-0052

*Address correspondence to: Joyce E. Parker (joyce.parker@nifa.usda.gov).

() 2016 J. E. Parker and D. J. Wagner. CBE-Life Sciences Education @ 2016 The American Society for Cell Biology. This article is distributed by The American Society for Cell Biology under license from the author(s). It is available to the public under an Attribution-Noncommercial-Share Alike 3.0 Unported Creative Commons License (http://creativecommons.org/licenses/ by-nc-sa/3.0).

"ASCB®" and "The American Society for Cell Biology $\circledR^{\prime \prime}$ are registered trademarks of The American Society for Cell Biology. 
and competitive funds to support the creation of a safe and competitive agricultural system. Many of NIFA's educational programs are led by the Division of Community and Education (DOCE), although students are also supported through grants administered by other divisions in NIFA. This review is not an exhaustive list of NIFA's educational grants but highlights specific funding opportunities supported through DOCE. For more information on formal and nonformal educational programs offered by various USDA agencies, please visit the USDA website (www.usda.gov/wps/portal/usda/usdahome).

\section{CURRENT AGRICULTURAL EDUCATION: AN OVERVIEW OF RELATED EFFORTS AT NIFA DOCE}

DOCE provides continued support for student and teacher training, development of educational tools and materials, and the development of a diverse food and agricultural workforce. DOCE also serves programs that target minority-serving institutions. Minority-serving institutions are defined as colleges and universities that provide educational opportunities for those who have historically faced inequality in their access to higher education. These include the 1890 and 1994 land-grant institutions as well as Hispanic-serving institutions. In this article, we focus on grant programs that fall under the three main goals of DOCE: to enhance 1) workforce development, 2) learning and engagement, and 3) capacity building.

1. Workforce development supports the development of the agricultural workforce through fellowship opportunities for undergraduate, graduate, and postdoctoral students and professional development opportunities for secondary school teachers.

2. Learning and engagement emphasizes the critical need to provide leading-edge training and learning opportunities for students. These investments include support for experiential learning opportunities, teacher training, curriculum development, and development of methods to improve the recruitment and retention of students.

3. Capacity building at minority-serving institutions and institutions outside the land-grant system facilitates access to higher education, supporting research, teaching, and extension activities to benefit students and communities served by these institutions.

The following sections provide information about existing funding opportunities within DOCE and identify examples of specific projects funded within those programs.

\footnotetext{
Programs Designed to Support Workforce Development Food, Agriculture, Natural Resources and Human Sciences Education and Literacy Initiative (AFRI ELI)-Formerly the AFRI NIFA Fellowships Grant Program. AFRI is NIFA's flagship grants program. AFRI provides funding for fundamental and applied research, extension, and education to address food and agricultural sciences and focuses on the following priority areas:

- Plant health and production and plant products

- Animal health and production and animal products

- Food safety, nutrition, and health

- Bioenergy, natural resources, and environment

- Agricultural systems and technology

- Agricultural economics and rural communities
}

Within AFRI ELI there are multiple funding opportunities, including predoctoral, postdoctoral, and undergraduate fellowships and professional development for secondary school teachers. Predoctoral and postdoctoral fellowships can be converted to standard grants in certain circumstances after the fellow has completed at least one year in the fellowship.

AFRI ELI Predoctoral and Postdoctoral Fellowships. This program prepares the next generation of agricultural scientists through predoctoral and postdoctoral fellowships, providing funding to enhance technical and functional competence, research independence, and acquisition of teaching credentials. The predoctoral and postdoctoral program is unique in that the student or postdoc serves as the project director and the faculty member serves as the mentor.

Sample project: Can Reduced-Input Farming Restore Biocontrol Communities Degraded by Climate Change? This NIFA Postdoctoral Fellowship project provided insight on how organic agriculture influences the distribution of pest and natural pest control and on how an ecosystem will respond to the challenges posed by climate change. The researchers conducted a meta-analysis of data collected throughout potato fields in Washington State and found that organic farms and conventional farms did not differ in natural enemy levels; however, the distribution of predators differed markedly. This research suggests implications for global climate change. Climate change is degrading global diversity, and in agriculture, this can translate to weaker biological control; an ecosystem service dependent on high levels of natural enemy biodiversity may be adversely affected, which may worsen pest outbreaks.

AFRI ELI Research and Extension Experiential Learning for Undergraduates (REEU) Fellowships. REEU promotes research and extension experiential learning for undergraduates, helping them to be ready to enter the agricultural workforce with exceptional skills. REEU programs provide hands-on experience at both land-grant and non land-grant universities and at USDA facilities. This program provides undergraduate students with strong mentoring, research, and/or extension experiences, enabling them to be successful in their continued studies. REEU is in its first year of funding, and no sample project is available.

Higher Education Multicultural Scholars Program (MSP). Funding through the MSP awards scholarships to outstanding students from groups traditionally underrepresented in the food and agricultural sciences to encourage these students to pursue and complete their education at the baccalaureate and/or doctor of veterinary medicine (DVM) degree level.

Sample project: Interdisciplinary Training for Multicultural Undergraduate Scholars in Agroecology and Natural Resource Sciences at Florida International University. MSP provided funding to recruit and train outstanding multicultural minority undergraduate and graduate students in food and agricultural sciences. Scholars were supported through research opportunities, internships, community engagement, and special experiential-learning activities. Scholars gained scientific skills by analyzing soils, waters, soil microbes, and soil nutrients. 
National Needs Graduate and Postgraduate Fellowship (NNF) Program. NNF provides funding to support students' training and completion of masters' and/or doctoral degree programs in identified national needs areas within the food, agricultural, natural resources, and human sciences. In fiscal year 2015, six national challenge areas NIFA were addressed:

- Agricultural and natural resources sciences for climate variability

- Childhood obesity prevention

- Food safety

- Food security

- Sustainable bioenergy

- Water resources

Sample project: Multidisciplinary Doctoral Training in Human Nutrition and Childhood Obesity. NNF provided funding to support a multidisciplinary doctoral training program in human nutrition and childhood obesity at the University of Arizona. This program provided courses and experiential learning resulting in core competencies through team science, laboratory rotations, grant and manuscript writing, scientific presentations, dissertation research, online and face-to-face teaching, and an outreach project in public education.

\section{Programs to Support Learning and Engagement}

The Higher Education Challenge (HEC). Projects supported by the HEC focus on educational needs and develop a nontraditional approach to address that need. HEC encourages and facilitates improved working relationships among the university science and education communities and the private sector to enhance program quality and supplement available resources.

Sample project: Healthy Animals Safe Food: A Comprehensive Web-Based Educational Tool to Enhance Food Safety Training of Veterinary Medical Students. HEC funded a 2014 project (in progress) that is developing a comprehensive Web-based educational tool to enhance food safety training of veterinary medical students. This project's goal was to improve pre- and postharvest food safety knowledge, relevant Spanish language abilities, mental motivation, and self-efficacy regarding food safety for these students, maximizing the education resources available and building partnerships to this end.

Secondary Education, Two-Year Postsecondary Education, and Agriculture in the K-12 Classroom Challenge Grants Program (SPECA). SPECA supports innovative curriculum development and teacher training in agriculture at $\mathrm{K}-12$ levels and community colleges in order to advance excellence in education and encourage students to pursue and complete a baccalaureate or higher degree in the food and agricultural sciences.

Sample project: New York Harbor Oyster Nursery Aquaculture Education Project. SPECA provided funding to support the New York Harbor Foundation School, which set up a 50-acre off-bottom oyster farm with the option to expand the acreage in the future. The farm is part of the school's aquaculture education program, which provides both vocational and college preparation programs in aquaculture and water ecology. Students participate in one of three available tracks: oyster aquaculture, oyster restoration, or marine biology.

\section{Programs Designed to Support Capacity Building at Minority-Serving Institutions}

Hispanic-Serving Institution (HSI) Education Grants Program. The HSI Education Grants Program supports innovative teaching or education proposals with the potential to impact HSIs and become models for other institutions that serve underrepresented students at the regional and national level. The primary focus of HSI grants is on improving teaching with the aim of increasing enrollment and graduation rates.

Sample project: Boots to Roots: Preparing Veterans in the Agricultural and STEM Degrees. An HSI grant is supporting a new program at Texas State University called Boots to Roots. This program helps female and Hispanic military veterans earn a bachelor's degree in agriculture or other STEM degree programs. Students who participate in Boots to Roots will acquire hands-on experience at Texas State's Student Sustainable Farm, engage in faculty-led and mentored undergraduate research, and present their research at conferences.

1890 Capacity-Building Grants Program. The 1890 landgrant institutions are historically black universities that were established under the Second Morrill Act of 1890. The 1890 programs provide support for research, extension, and teaching, aiming to build the institutional capacities of the 1890 institutions.

Sample project: An Economic Analysis of the Local Food Environment and Demand for Fruits and Vegetables in a Food Desert Cluster in Tennessee: Implications for Ameliorating Obesity and Promoting Healthy Diet. An 1890s grant program provided support to an ongoing research project at Tennessee State University's Department of Agricultural and Environmental Sciences. The project investigated the economics of food deserts and demand for fruits and vegetables. Food deserts are defined by the USDA as low-income communities where at least 500 citizens or $33 \%$ of the community live a mile or more away from a supermarket or grocery store with fresh produce. The project's goal was to help the community improve its food access and nutritional status by understanding how this community differs from neighboring towns and the potential contributing community factors, such as poverty and limited nutritional awareness.

Tribal Programs. NIFA's Tribal Programs provide learning support at the 1994 land-grant schools, also known as federally recognized tribal colleges. In addition, the Federally Recognized Tribes Extension Program supports 1862 and 1890 land-grant schools that provide informal, community-based learning on reservations.

Sample project: Promoting Traditionally-based Healthy Lifestyles for Children, Youth and Families of the Flathead Indian Reservation. The Tribal Programs provided support to Salish Kootenai College, located in Pablo, Montana, for development of their Making Fitness Fun program. The program runs 40 days in the summer and involves hiking, swimming, native games, sports, and other activities. The summer program emphasized both traditional health messages and nutritional messages. The college reached more than 200 youth in its summer program. Another big part of the programming was native games (double ball, shinny, stickball). The college held 15-20 native games events throughout the year, impacting more than 700 participants yearly. The project goal was to teach health 
and fitness lessons early in order for them to have a lifetime effect.

\section{CONCLUSION}

For readers who are interested in preparing projects and proposals for submission to the programs discussed above or others at NIFA, we recommend accessing the NIFA website (www.nifa .usda.gov) and reading the appropriate program's request for application (RFA). The eligible applicants will vary from grant to grant, and this is discussed in detail under "Eligibility Information" in each RFA. More targeted questions can be addressed to that program's national program leader; program leaders can be found on the NIFA website and associated RFAs. For more information regarding NIFA-awarded projects, please use the Current Research Information System database (http://cris .nifa.usda.gov), which provides documentation and reporting for ongoing agricultural, food science, human nutrition, and forestry research, as well as education and extension activities for the USDA.

\section{ACKNOWLEDGMENTS}

We thank Siva Sureshwaran for comments on the manuscript and Jill Lee and Josue Lopez for assistance in providing examples of funded opportunities.

\section{REFERENCES}

Allen D, Woodin T (2009). Current developments and funding opportunities in life sciences education. CBE Life Sci Educ 8, 95-99.

Goecker A, Smith E, Fernandez JM, Ali R, Goetz R (2015). Employment Opportunities for College Graduates in Food, Agriculture, Renewable Natural Resources, and the Environment. www.purdue.edu/usda/ employment (accessed 29 February 2016).

Labov JB, Reid AH, Yamamoto KR (2010). Integrated biology and undergraduate science education: a new biology education for the twenty-first century? CBE Life Sci Educ 9, 10-16. 